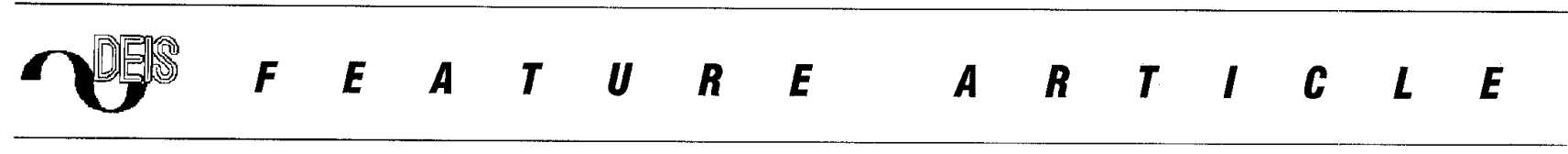

\title{
Moisture Equilibrium in Transformer Paper-Oil Systems
}

Key Words: Transformer paper, transformer oil, moisture equilibrium, vapor pressure, relative humidity

$\mathrm{T}$ he presence of moisture in a transformer deteriorates transformer insulation by decreasing both the electrical and mechanical strength. In general, the mechanical life of the insulation is reduced by half for each doubling in water content [1]; the rate of thermal deterioration of the paper is proportional to its water content [2]. Electrical discharges can occur in a high voltage region due to a disturbance of the moisture equilibrium causing a low partial discharge inception voltage and higher partial discharge intensity [3]. The migration of a small amount of moisture has been associated with flow electrification at paper/oil interfaces and is presumed to be due to charge accumulation on highly insulating interfacial dry zones $[4,5]$. Water in mineral oil transformers also brings the risk of bubble formation when desorption of water from the cellulose increases the local concentration of gases in the oil [6]. The importance of moisture presence in paper and oil systems has been recognized since the 1920 s.

It is useful to know the moisture partitioning curves between oil and paper under equilibrium conditions. When the transformer is in equilibrium operation, this provides a quick way of examining the moisture content in paper to predict future failure by measuring the moisture in oil. Over the years, many scientists have reported such a set of curves, but there has not been a comprehensive review and comparison for different curve sets. The research spans several decades and is an important resource for electric utilities and insulation and testing equipment manufacturers. This paper gives an overview of the classic moisture equilibrium curves and their history and provides useful information on the relationships among them and their validity.

\section{Background}

An excellent review of the basic concepts that are used in this paper is given in [7]. A brief introduction is given here.

\section{Transformer Oil}

Mineral transformer insulating oils are refined from predominantly naphthenic crude oils. The refining processes could include acid treatment, solvent extraction, dewaxing, hydrogen treatment, or combinations of these

\section{Y. Du, M. Zahn, B.C. Lesieutre, and}

A.V. Mamishev

Department of Electrical Engineering and Computer

Science, Massachusetts Institute of Technology

\section{and S. R. Lindgren}

Electric Power Research Institute

The presence of moisture in solid and liquid transformer insulation plays a critical role in transformer life.

methods to yield mineral insulating oil meeting the specification. It is mainly a mixture of hydrocarbon compounds of three classes: alkanes, naphthenes, and aromatic hydrocarbons. These molecules have little or no polarity. Polar and ionic species are a minor part of the constituents, which may greatly influence the chemical and electrical properties of the oil. "Polar compounds found in transformer oil usually contain oxygen, nitrogen, or sulfur. Ionic compounds would typically be organic salts found only in trace quantities" [7]. For a more complete review on transformer oil, refer to [8].

\section{Water in Oil}

Insulating oils, such as transformer oil, have a low affinity for water. However, the solubility increases markedly with temperature for normally refined naphthenic transformer oil. This will be discussed more quantitatively later in this paper. Water can exist in transformer oil in three states. In practical cases, most water in oil is found in the dissolved state. Certain discrepancies in examining the moisture content using different measurement techniques suggest that water also exists in the oil tightly bound to oil molecules, especially in deteriorated oil. When the moisture in oil exceeds the saturation value, there will be free water precipitated from the oil in suspension or drops. Moisture in oil is measured in 
parts per million (PPM) using the weight of moisture divided by the weight of oil $(\mu \mathrm{g} / \mathrm{g})$.

\section{Relative Humidity}

Relative humidity can be defined in terms of the moisture mixing ratio $r$ versus the saturation mixing ratio $r_{\mathrm{s}}$, R.H. $\%=$ $100 r / r_{s}$, which is a dimensionless percentage. Relative humidity for air is the water vapor content of the air relative to its content at saturation. Relative humidity for oil is the dissolved water content of the oil relative to the maximum capacity of moisture that the oil can hold. Because the saturation mixing ratio is a function of pressure, and especially of temperature, the relative humidity is a combined index of the environment and reflects more than the water content [9].

\section{Paper}

The following four terms are often used interchangeably in the context of solid transformer insulation: pressboard, paper (or Kraft paper), transformerboard, and cellulose. Although in the context of particular transformer insulation they may indicate different parts, e.g., paper tape, paper cylinders, transformerboard cylinders, angle rings, blocks, etc., in the context of moisture equilibrium, they all in general refer to electrical-grade paper insulation manufactured from unbleached sulfate cellulose, consisting of a more or less long chain of glucose rings. Pressboard has been well known in the textile and paper processing industries for more than 100 years and was used in the first electric machines. Transformerboard resulting from the efforts of Hans Tschudi-Faude of H. Weidmann Ltd. in the late 1920 s [3] is a better type of pressboard meeting the requirements of large power transformers. It is made with high-grade sulfate cellulose and consists solely of pure cellulose fibers without any binder. It can be completely dried, degassed, and oil impregnated. Insulation paper can be manufactured to different density, shape, and other properties for different applications.

\section{Water in Paper}

Water in paper may be found in four states: It may be adsorbed to surfaces, as vapor, as free water in capillaries, and as imbibed free water. The paper can contain much more moisture than oil. For example, a $150 \mathrm{MVA}, 400 \mathrm{kV}$ transformer with about seven tons of paper can contain as much as $223 \mathrm{~kg}$ of water [10]. The oil volume in a typical power transformer is about 80,000 liters. Assuming a 20 PPM moisture concentration in oil, the total mass of moisture is about $2 \mathrm{~kg}$, much less than in the paper. The unit for moisture concentration in paper is typically expressed in \%, which is the weight of the moisture divided by the weight of the dry oil-free pressboard.

\section{Water Vapor Pressure}

Water vapor pressure is the partial pressure exerted by water vapor. When the system is in equilibrium with the liq- uid or solid form, or both, of the water, it reaches the saturation water vapor pressure. Saturation vapor pressure is a measure of the tendency of a material to change into the gaseous or vapor state, and it increases with temperature. At the boiling point of the water, the saturation water vapor pressure at the surface of water becomes equal to the atmospheric pressure.

\section{Overview}

\section{Fabre-Picbon Curves}

The moisture-equilibrium curve for an oil-paper complex was first reported by Fabre and Pichon [2] in 1960 and is shown in Fig. 1. It is the most widely cited set of curves. The paper used was Kraft paper and an air-paper-oil complex was studied. A later summary of the work carried out at the same laboratory by Fallou [11] states that the moisture content of the oil and

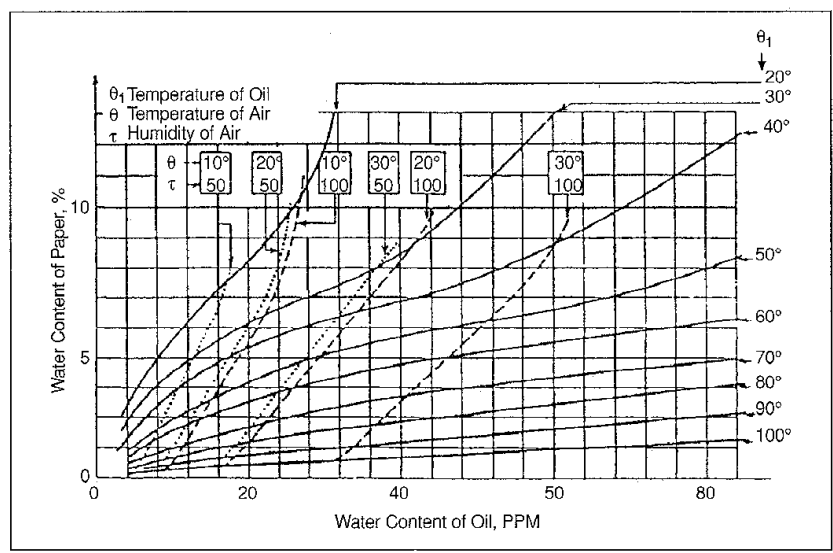

Fig. 1 Fabre-Pichon curves for moisture equilibrium of the air-oil-paper complex as a function of the air and oil surrounding the paper. Figure is taken from [2] except labels are translated into English.

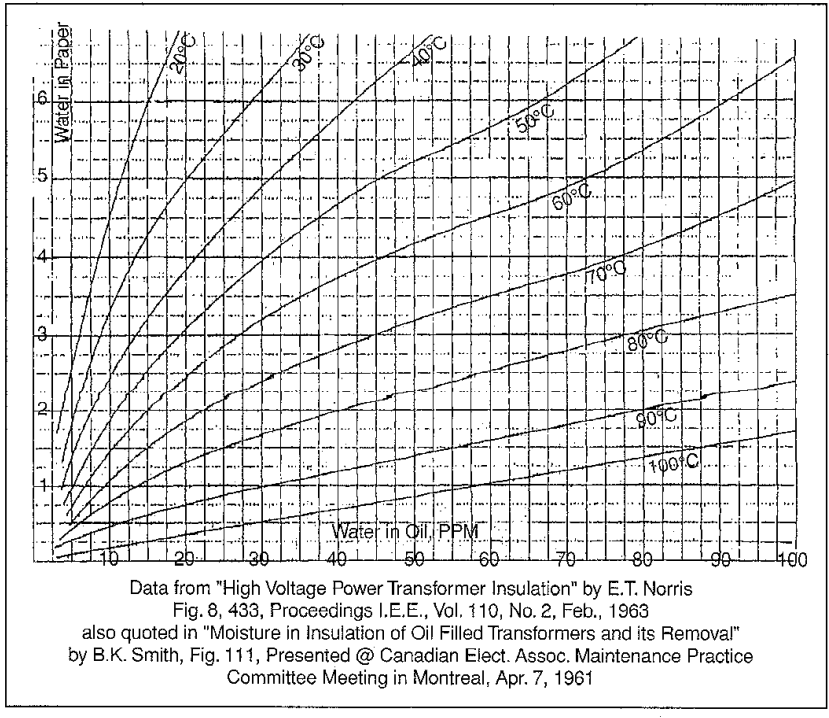

Fig. 2 Curves redrawn by EHV-Weidmann for moisture equilibrium of the oil-paper system 
oil-impregnated pressboard were directly measured by the Karl Fischer reaction method.

The paper emphasized the equilibrium law, which is similar to the principle that Oommen used in [12] to indirectly obtain the moisture equilibrium curves for oil-paper systems: "The relative humidity (that is to say, referred to saturation value) is the same in the oil and in the air in contact with one another at the same temperature [13]." This was proved to be true within the limits of the experimental procedures done by General Electric in 1960 [14].

In 1963, Norris referred to the Fabre-Pichon curves in Fig. 8 of his paper [15]. Thus these curves became "affectionately" known as the "Norris Curves" even though they were originally published in Fabre-Pichon's paper [2]. EHV/Weidmann Industries, Inc., St. Johnsbury, Vt., a company specializing in transformerboard manufacturing, redrew the curves shown in Fig. 2 and credited Norris by noting data from [15]. Similarly, they are noted as "Norris Curves" in Fig. 3 of [16], and Fig. 5.4 of [17].

One possible reason for these historical mistakes is that Norris was perhaps the earliest exponent of the moisture transient processes in transformers. The other cause might be that Fabre-Pichon's paper [2] was published by CIGRE and is not a document that can be easily accessed by the public. The original paper was in French-even the translated one still has French for all the figures. Many other people redrew the curves in a different format and the true source was lost.

\section{Dommen Curves}

In 1983 Oommen developed a set of moisture equilibrium curves, published in [12] and shown in Fig. 3 . Oommen's method is based on the principle that the equilibrium curves represent the same relative saturation for the oil and for the paper at the same temperature. He combined the Moisture in Oil versus Relative Humidity curves in air with Moisture in Paper versus Relative Humidity curves in air to make the Moisture in Paper versus Moisture in Oil equilibrium curves.

The Moisture in Oil versus Relative Humidity curves are straight lines with the relationship

$$
x_{w}=x_{w}^{s} \times R \cdot H .
$$

where $x_{w}$ is the moisture in oil in PPM, $x_{w}^{s}$ is the water solubility in oil in PPM, and R.H. is the relative humidity of oil.

Oommen used the oil equilibrium curves along with the Moisture in Wood Pulp versus Relative Humidity Curves made from Jeffries' data [18] shown in Fig. 4 and generated the moisture equilibrium curves for a paper-oil system shown in Fig. 3. The dashed lines indicate desorption curves (diffusion of moisture out of cellulose), whereas the solid lines indicate the adsorption curves (diffusion of moisture into cellulose). For the same relative humidity, the moisture content of the desorption curves is slightly higher than that of the adsorption curves.

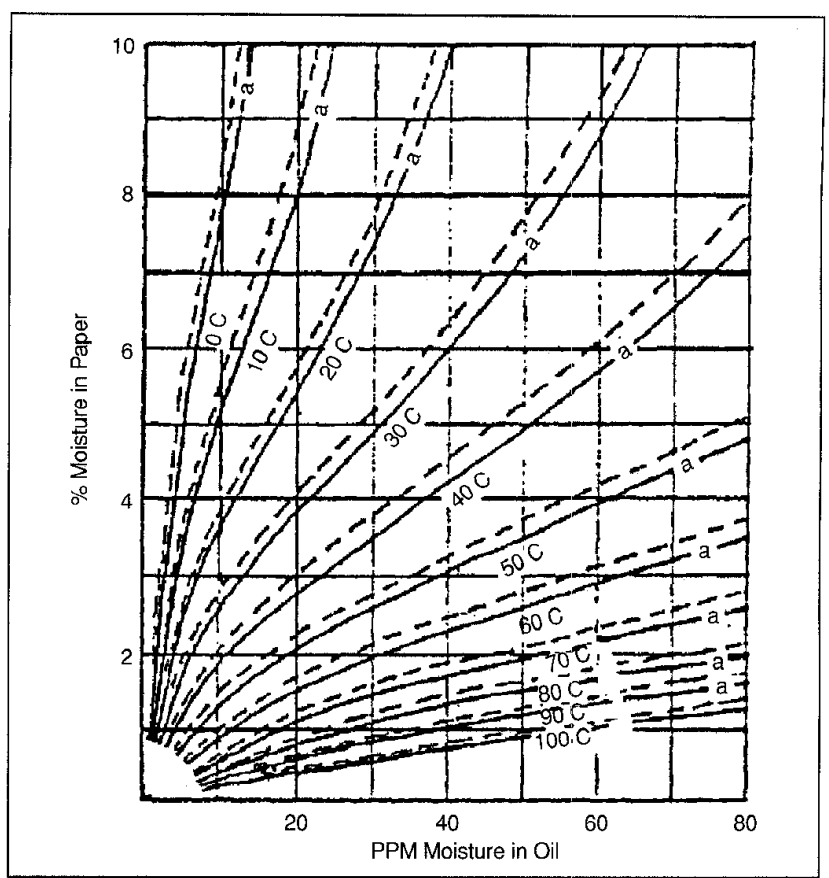

Fig. 3 Oommen's curves for moisture equilibrium for a paper-oil system [12]

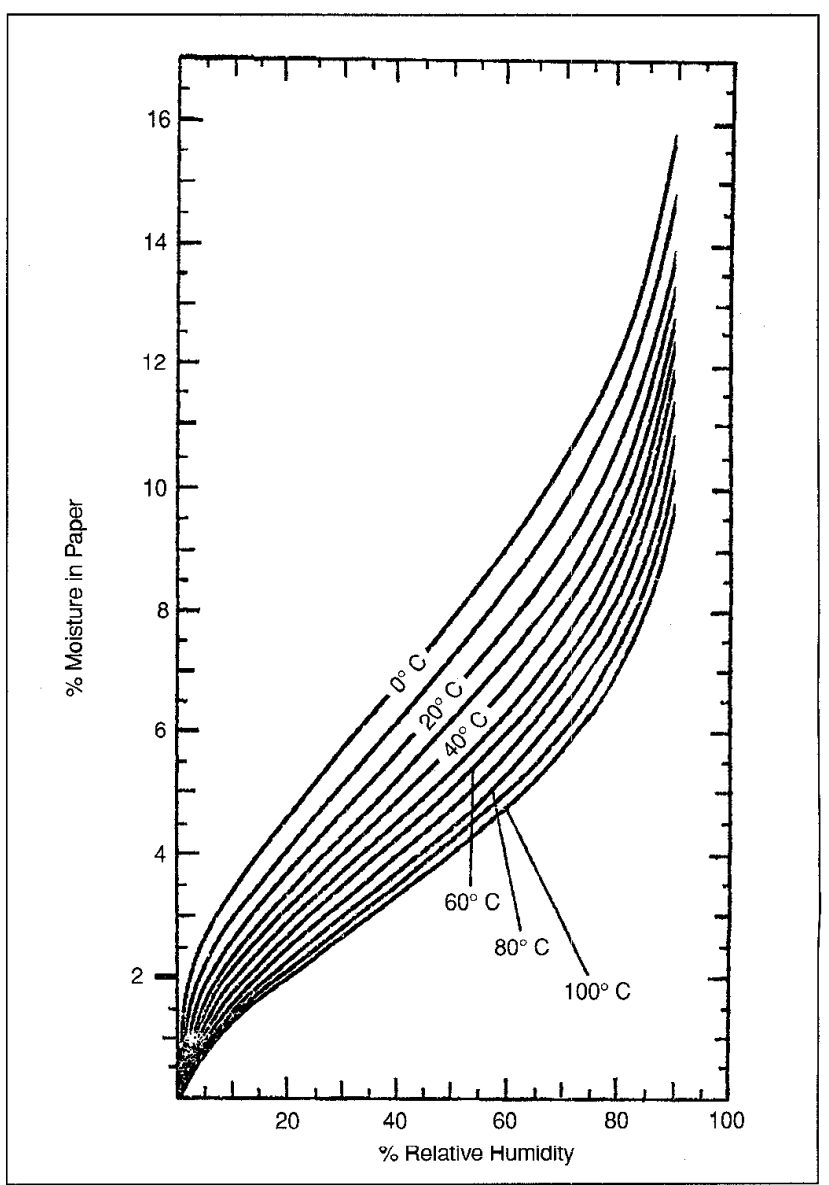

Fig. 4 Moisture in wood pulp as a function of relative humidity of the ambient by Jeffries [18]. Picture supplied by Oommen at ABB-ETI who redrew Jeffries' data. 


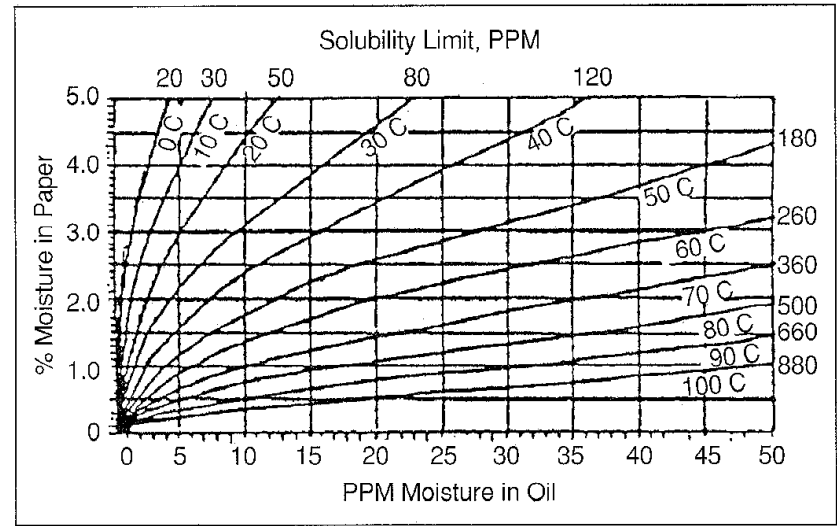

Fig. 5 Oommen curves for low moisture region of moisture equilibrium for paper-oil system [12]

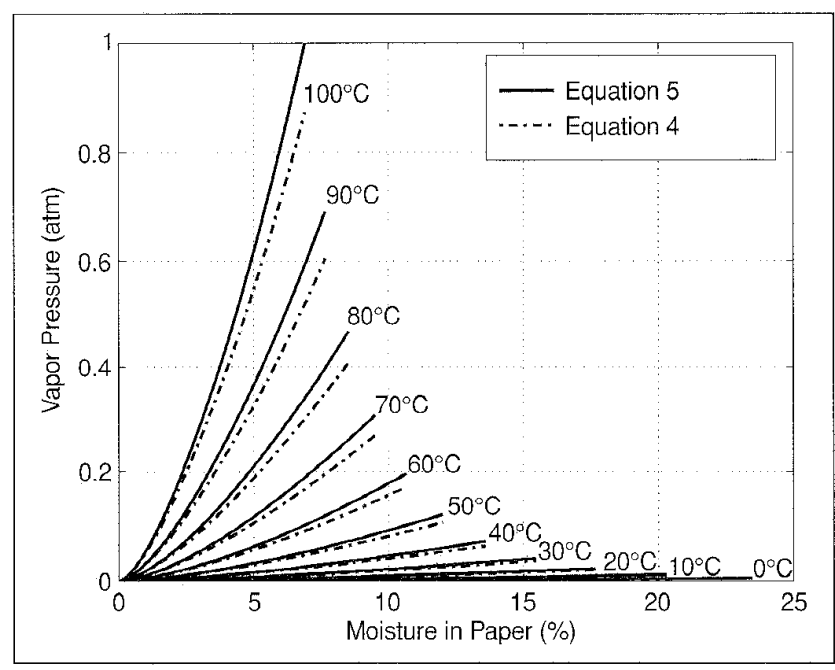

Fig. 6 Vapor pressure versus moisture in paper comparing the erroneous formula (4) and the correct formula of (5)

As pointed out by Reason in [19], if the relative humidity of the oil is measured by commercially available sensors, Jeffries's data in Fig. 4 can be directly used to estimate the moisture concentration in the pressboard.

Fig. 3 is not very reliable in the low moisture range due to the impractical conditioning of paper below $10 \%$ relative humidity. Hence, Oommen used the data of the vapor pressure of water in the gas space above the sample in a sealed system reported by Beer et al. in 1966 [10] and converted to relative humidity by the relationship

$$
\% \text { R.H. }=\left(\frac{p}{p_{0}}\right) \times 100
$$

where $p_{0}$ is the saturated water vapor pressure [20] and $p$ is the water vapor pressure.

Combining the sorption curves for paper and oil again, Oommen constructed the sorption curves for the low moisture region as shown in Fig. 5 .

\section{Equilibrium Curves for Water Vapor Pressure and Moisture Content}

From both Fabre and Oommen's statements, we see that the equilibrium curves for water vapor pressure and moisture content in paper can be used to derive the partition curves between oil and paper. Thus it is worthwhile to look at the evolution of this set of curves.

- Piper (1946)

Among the families of equilibrium curves for water vapor pressure and moisture concentration of oil-free paper curves, the early and most widely used by manufactures and utilities was reported by Piper [21] in 1946. Piper combined four groups of data from literature to get a full set of curves: 1) data for cotton in high moisture concentration from Urquhart and Williams [22]; 2) data for cotton of low moisture content from Neale and Stringfellow [23]; 3) data for Kraft paper of low moisture content at elevated temperatures from Houtz and McLean [24]; and 4) data for spruce wood of high moisture content from Pidgeon and Maass [25]. By interpolation and extrapolation of experimental data, Piper derived that for the same vapor pressure, the moisture in Kraft paper is 1.7 times that of cotton.

- Jeffries (1960)

This factor of 1.7 was then considered to be too high by Jeffries in 1960 compared with his data [18].

- Beer et al. (1966)

In 1966, Beer et al. measured the water vapor adsorption curves for Kraft paper by a modified Edwards' apparatus [10]. In the sense of completeness, Beer's curve is apparently improved over Piper's because all Beer's data were obtained for Kraft paper directly.

- Ewart (1974)

A paper by Guidi and Fullerton [26] covered the work performed by Ewart. Ewart's data also suggested that the paper water contents derived from cotton by Piper are too high.

- Oommen (1984)

Beer's charts were not widely adopted, partly because they were not in a form that could be conveniently used. Oommen in 1984 [27] reconstructed similar charts using the data from Beer et al. By comparison, he found the new charts will give slightly lower estimates of the moisture content for a given vapor pressure and temperature than the Piper chart.

- Fessler et al. (1987)

Fessler et al. [6] needed an accurate formula to build a model for bubble formation in transformers. Noticing the differences in the literature, they directly measured the moisture in paper and the moisture vapor pressure and did a comparison with existing reports [6]. Their results showed that the Piper database tends to be higher than any of the other databases and all of the other data are in reasonably good agreement. Fessler et al. combined the data from Houtz [24], Ewart [26], Oommen [27] and their own experiments and determined a water-paper equilibrium formula:

$$
C=2.173 \times 10^{-7} \times P_{v}^{0.6685} \times e^{(4725.6 / T)},
$$


where $\mathrm{P}_{\mathrm{v}}$ is the vapor pressure of water in atmosphere, $\mathrm{C}$ is the concentration of water in paper $\left(\mathrm{g} \mathrm{H}_{2} \mathrm{O} / \mathrm{g}\right.$ Paper $)$, and $\mathrm{T}$ is the absolute temperature in degrees Kelvin. The water vapor pressure as a function of water concentration and temperature is also given in the report:

$$
P_{V}=5.8869 \times 10^{9} \times C^{1.4495} \times e^{(-6996.7 / T)},
$$

However, from an algebraic inversion of (3), the correct pressure relation is:

$$
P_{V}=9.2683 \times 10^{9} \times C^{1.4959} \times e^{(-7069 / T)},
$$

which significantly differs from (4). It appears that the derivation of (4) from (3) had an algebraic error. The difference between the two types of curves is shown in Fig. 6.

Fig. 6 further demonstrates that equation (4) is not the inverse of (3) because the calculated $\mathrm{P}_{\mathrm{v}}$ at the highest concentration at $100^{\circ} \mathrm{C}$ should be one atmosphere.

Using (2), we can also construct curves for Moisture in Paper versus Relative Humidity shown in Fig. 7 for formulas (4) and (5). There are large differences for the high relative humidity levels between the experimental data in Fig. 4 and the fitted data in Fig. 7. Oommen in [12] pointed out that the sorption curves cannot be fitted exactly by any mathematical relationship for the entire range. A multi-layer adsorption model predicts a sharp rise in moisture adsorption after $50 \%$ RH [28]. Both Jeffries's curves in Fig. 4 and the Moisture in Paper versus Relative Humidity curve in Fig. 1 of Ewart's report [14] show that the slope increases at high relative humidity level. Fessler et al.'s [6] curves flatten out at the high end, which indicates a possible error of the model for the high relative humidity region.

Oommen [29] also found that the prediction of bubble evolution temperature using the mathematical model developed in [6] is off by $50^{\circ}$ in gas-saturated systems. His study [29] gave the correct experimental results.

\section{Griffin's Curves}

Griffin et al. at Doble Engineering in 1988 made similar curves for mineral oil and paper using Oommen's method [30]. The mineral oil refers to a typical naphthenic-based electrical insulating mineral oil.

They used Fessler's formula (4) for vapor pressure and then converted to relative humidity using (2). Their original curves are shown in Fig. 8. A comparison is given in Fig. 9 for using (4) and (5).

\section{MIT Curves}

All of the above curves available in the literature are up to at most 100 PPM moisture in oil because the primary concern of moisture concentration in the transformer environment is within that range. However, our laboratory experiments that operate at high moisture concentrations require the curves to cover a wider range. Using Oommen's method and Jeffries's curves, we generated a wider range of equilibrium curves from $0^{\circ} \mathrm{C}$ to $100^{\circ} \mathrm{C}$ and moisture in oil

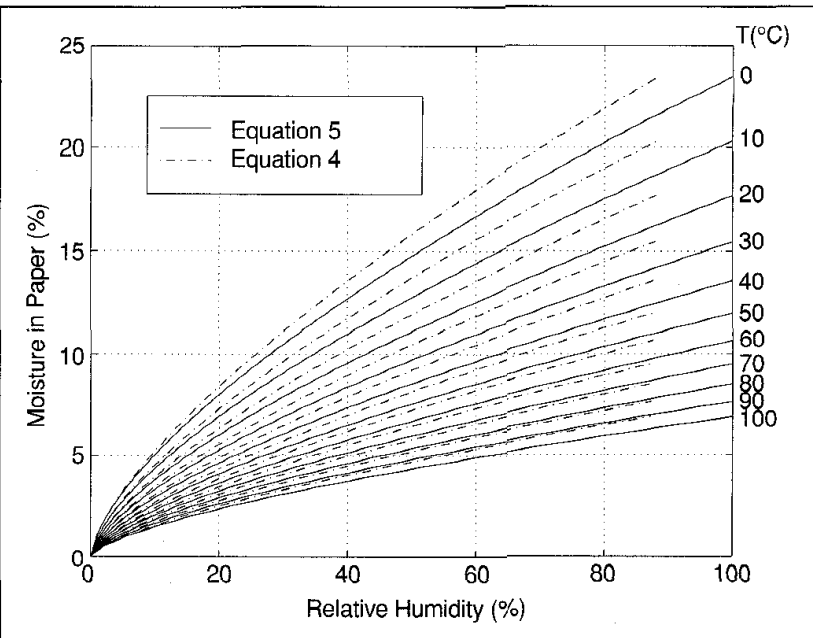

Fig. 7 Moisture in paper versus ambient relative humidity curves comparing erroneous (4) and correct (5)

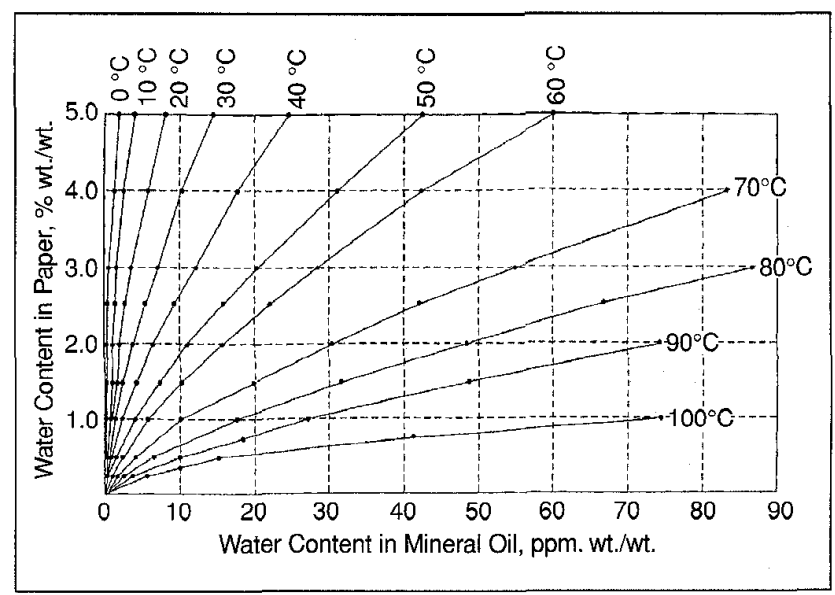

Fig. 8 Griffin curves for water equilibrium in cellulose/mineral oil systems [30]

up to 800 PPM shown in Fig. 10. For water in paper below 1\%, we used Oommen's curves in Fig. 5.

\section{Comparison}

\section{Direct Measurement versus Indirect Measurement}

The advantage of Oommen's method is that it is much easier to determine the water equilibrium between the gas space and paper without the presence of the liquid insulation, as the moisture diffusion coefficients of oil-impregnated pressboard are about two orders of magnitude smaller than those of oil-free pressboard. Foss in 1987 [31] generalized the empirical work by Ast [32] and Steele [33] at General Electric and fitted a diffusion coefficient as a function of temperature $\mathrm{T}$ in ${ }^{\circ} \mathrm{K}$ and moisture concentration $C$ in percent by weight as:

$$
D=D_{0} \exp \left[0.5 C+E_{a} \times\left(1 / T_{0}-1 / T\right)\right]
$$

where $\mathrm{T}_{0}=298^{\circ} \mathrm{K}$, and for oil-free and oil-impregnated paper: 


$$
\begin{aligned}
& E_{a}=8140^{\circ} \mathrm{K}, D_{0}=2.62 \times 10^{-11} \mathrm{~m}^{2} / \mathrm{s}, \quad \text { oil-free } \\
& E_{a}=8074^{\circ} \mathrm{K}, D_{0}=1.34 \times 10^{-13} \mathrm{~m}^{2} / \mathrm{s}, \quad \text { oil-impregnated }
\end{aligned}
$$

In an earlier paper by Guidi and Fullerton [26], different coefficients are given for oil-impregnated Kraft paper from data studied by Ewart:

$$
E_{a}=7700^{\circ} \mathrm{K}, D_{0}=6.44 \times 10^{-14} \mathrm{~m}^{2} / \mathrm{s} \text {. }
$$

A comparison of diffusion coefficients D and the diffusion time $\tau$ for a piece of $1 \mathrm{~mm}$ thick pressboard with typical

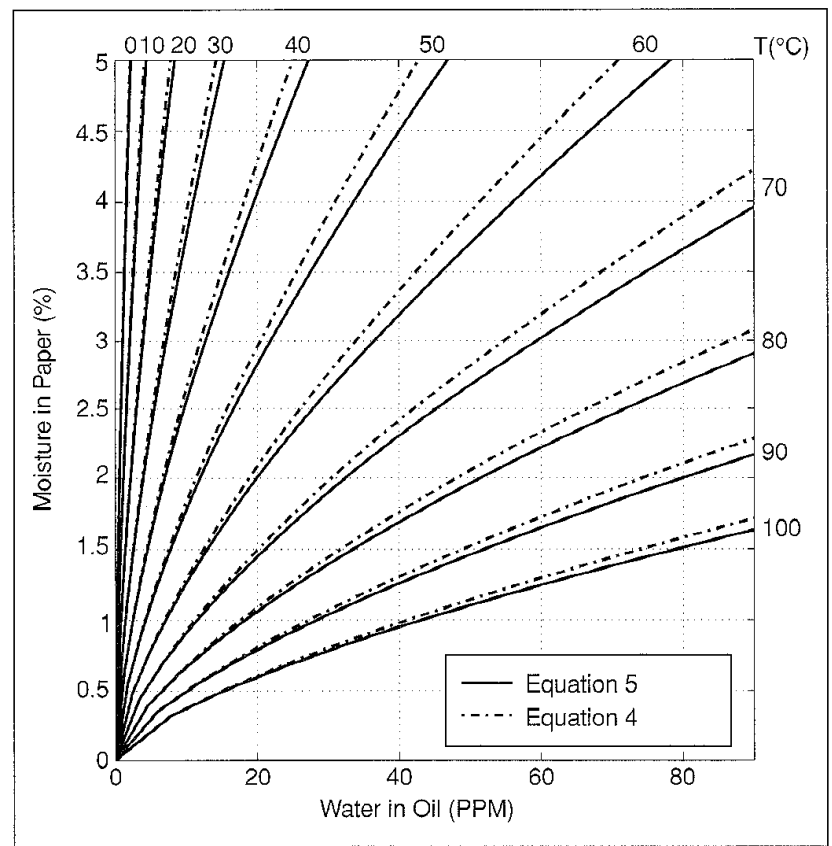

Fig. 9 Regenerated curves following Griffin's procedure using erroneous (4) and correct (5)

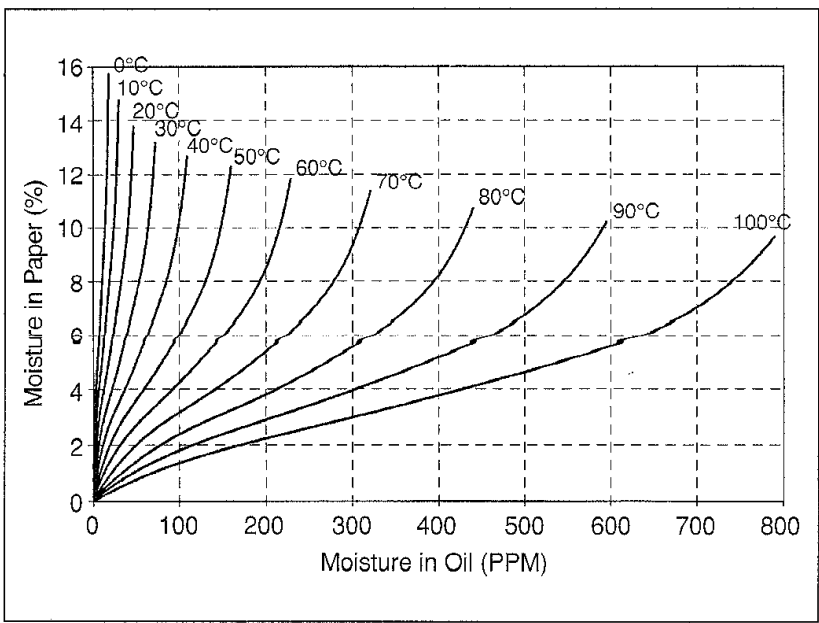

Fig. 10 MIT-developed curves for water equilibrium in cellulose/mineral oil systems for a wide range of moisture concentrations moisture concentration after drying of $0.5 \%$ are given in $\mathrm{Ta}$ ble I using Foss's formula. The diffusion time constant for moisture diffusing from both sides is calculated as

$$
\tau=\frac{d^{2}}{\pi^{2} D^{\prime}}
$$

where $d$ is the thickness of pressboard. The diffusion time constant for moisture diffusing from one side is

$$
\tau=\frac{4 d^{2}}{\pi^{2} D}
$$

This shows that the data for oil-impregnated pressboard is much more susceptible to be in a non-equilibrium condition than that of oil-free pressboard, particularly at low temperatures. That is why the direct measurement of the partitioning of the oil-papaer system is not practical.

\section{Water Solubility in Oil}

The water solubility for oil can be expressed in Arrhenius form as

$$
\log x_{w}^{s}=A-\frac{B}{T}
$$

where $x_{w}^{s}$ is the saturation solubility of water in oil in PPM and $T$ is the temperature in degrees Kelvin. Different coefficients $A$ and $B$ by different authors are shown in Table II, and the calculated oil solubility at different temperature is given in Table III.

\section{Curve Comparison}

\begin{tabular}{|c|c|c|c|c|}
\hline \multicolumn{5}{|c|}{$\begin{array}{c}\text { Table I: Comparison of Diffusion Coefficients by Foss [31] } \\
\text { and Diffusion Time for } 1 \mathrm{~mm} \text {-Thick Oil-Free and Oil-Impregnated } \\
\text { Pressboard using (6) and (9) with } C=0.5 \%\end{array}$} \\
\hline & \multicolumn{2}{|c|}{ Oil-Free Pressboard } & \multicolumn{2}{|c|}{ Oil-Impregnated Pressboarc } \\
\hline $\mathrm{T}$ & $20^{\circ} \mathrm{C}$ & $70^{\circ} \mathrm{C}$ & $20^{\circ} \mathrm{C}$ & $70^{\circ} \mathrm{C}$ \\
\hline $\mathrm{D}\left(\mathrm{m}^{2} / \mathrm{s}\right)$ & $1.7 \times 10^{-11}$ & $9.5 \times 10^{-10}$ & $8.5 \times 10^{-14}$ & $4.7 \times 10^{-12}$ \\
\hline $\begin{array}{l}\tau=d^{2} /\left(\pi^{2} D\right) \\
\text { (hours) }\end{array}$ & 1.7 & 0.03 & 333 & 0 \\
\hline
\end{tabular}

Due to the differences in the moisture solubility of oil, the moisture in paper versus relative humidity, and different measurement accuracy, the curves generated by different investigators show differences. A comparison for different moisture and temperature levels is shown in Table IV.

Table Il: Comparison of Estimated Parameters for the Arrhenius Form in Eq. (11) of the Solubility of Water in Transformer Oil

\begin{tabular}{|l|l|l|l|}
\hline & \multicolumn{1}{|c|}{ Oommen [12] } & \multicolumn{1}{|c|}{ Griffin [30] } & Shell [34] \\
\hline A & 7.42 & 7.09 & 7.30 \\
\hline$B$ & 1670 & 1567 & 1630 \\
\hline
\end{tabular}


Oommen's curves and MIT's curves are generated from the same source.

The curves are close to each other at low moisture concentration levels in paper. The moisture content in paper in Oommen's curve is consistently lower than that in Fabre and Griffin's for the same moisture concentration in oil. The ma-

\begin{tabular}{|l|l|l|l|}
\hline \multicolumn{4}{|c|}{ Table III: Water Saturation Solubility in Oil by Different Investigators } \\
\hline \multicolumn{1}{|c|}{ Oommen } & \multicolumn{1}{c|}{ Griffin } & \multicolumn{1}{c|}{ Shell } \\
\hline 0 & 20 & 23 & 22 \\
\hline 10 & 33 & 36 & 35 \\
\hline 20 & 53 & 56 & 55 \\
\hline 30 & 82 & 83 & 84 \\
\hline 40 & 122 & 122 & 124 \\
\hline 50 & 179 & 174 & 180 \\
\hline 60 & 255 & 243 & 255 \\
\hline 70 & 358 & 334 & 355 \\
\hline 80 & 491 & 450 & 484 \\
\hline 90 & 663 & 596 & 648 \\
\hline 100 & 880 & 777 & 855 \\
\hline
\end{tabular}

\begin{tabular}{|l|l|l|l|}
\hline \multicolumn{5}{|c|}{$\begin{array}{c}\text { Table IV: Comparison of Moisture Equilibrium in } \\
\text { Paper/Oil System by Different Authors }\end{array}$} \\
\hline \multicolumn{1}{|c|}{ Authors } & Fabre-Pichon [2] & Oommen [12] & Griffin [30] \\
\hline $\begin{array}{l}10 \mathrm{PPM} \\
70^{\circ} \mathrm{C}\end{array}$ & $1.1 \%$ & $1.0 \%$ & $1.0 \%$ \\
\hline $\begin{array}{l}10 \mathrm{PPM} \\
30^{\circ} \mathrm{C}\end{array}$ & $3.4 \%$ & $3.1 \%$ & $4.0 \%$ \\
\hline $\begin{array}{l}60 \mathrm{PPM} \\
60^{\circ} \mathrm{C}\end{array}$ & $4.5 \%$ & $2.9 \%$ & $5.0 \%$ \\
\hline $\begin{array}{l}80 \mathrm{PPM} \\
70^{\circ} \mathrm{C}\end{array}$ & $3.8 \%$ & $2.7 \%$ & $3.8 \%$ \\
\hline
\end{tabular}

\begin{tabular}{|c|c|}
\hline \multicolumn{2}{|c|}{ Table V: Quantitative Calculation of Moisture Transfer from Oil to Pressboard } \\
\hline $\begin{array}{l}\text { RH of oil at beginning (after T stabilized at } \\
70^{\circ} \mathrm{C} \text { ) }\end{array}$ & $43 \%$ \\
\hline RH of oil at equilibrium: & $32 \%$ \\
\hline Saturated mass fraction $\mathrm{x}(\mathrm{PPM})$ at $70^{\circ} \mathrm{C}$ & $x=353 P P M$ \\
\hline PPM moisture in oil at beginning & $P_{b}=R H \times 353 P P M=152 P P M$ \\
\hline PPIV moisture in oil in equilibrium & $P_{e}=R H \times 353 P P M=113 P P M$ \\
\hline PPM moisture diffuses to pressboard & $\Delta P_{W}=P_{b}-P_{e}=39 P P M$ \\
\hline Total weight of oil & $m_{\text {oll }} \approx 5300 \mathrm{~g}$ \\
\hline Total moisture diffused into pressboard & $\Delta m_{w}=m_{\text {ofl }} \bullet \Delta P_{w}=0.2 g$ \\
\hline Total weight of dry pressboard & $M_{p a p e r}=5.7 g$ \\
\hline$\%$ change of moisture in pressboard & $P_{\text {paper }}=\Delta m_{w} / m_{p}=3.5 \%$ \\
\hline
\end{tabular}

jor differences occur at low temperature, and at high concentration levels in paper with high temperature.

\section{Case Study}

An examination of the curves was carried out using experimental data. The paper-oil system was initially dried under vacuum and then the dry oil was removed and moist oil was introduced to the system. A three-wavelength interdigital sensor was used to monitor the moisture diffusion process $[35,36]$. The final moisture content in the pressboard and oil could be calculated using mass balance either from measurement or calculation using the oil-paper equilibrium moisture curves.

Method 1: The moisture diffusion from oil to pressboard is monitored in the oil using a Harley moisture meter as shown in Fig. 11. Since the system is sealed, the total moisture in the system is a fixed quantity, divided between oil and pressboard. By knowing the moisture in the oil at the beginning and in the end, the final moisture concentration in pressboard can be decided. Quantitative calculations are given in Table V. The initial moisture in the pressboard is assumed to be zero. This is justified by the small size of the pressboard sample and a good and thorough vacuum.

Method 2: We could not directly determine the amount of moisture in the pressboard in the equilibrium for our test from any of the published curves, since none of them gives moisture concentration in oil greater than 100 PPM while the equilibrium concentration is 113 PPM. However, by inspection, we found the Fabre-Pichon and Griffin curves would not fit the data, because even at 80 PPM those curves already indicate about $4 \%$ moisture in paper; the value that corresponds to 113 PPM would be more than $3.5 \%$ as estimated in Method 1. Using the MIT curves of Fig. 10, we got consistent values as illustrated in Fig. 12.

The straight line is the mass conservation curve based on the equation:

$$
P_{\text {paper }} \%=\frac{W_{\text {total }}-W_{\text {oil }}}{W_{\text {paper }}} \times 100
$$

where $\mathrm{W}_{\text {total }}(\mathrm{g})$ is the total moisture mass in the system, which is also the moisture in the oil at the beginning since we start with very dry pressboard; $\mathrm{W}_{\text {oil }}(\mathrm{g})$ is the moisture mass in oil during the experiment, which equals the water in oil in PPM times the total oil mass; $M_{\text {paper }}(\mathrm{g})$ is the mass of the pressboard, and $\mathrm{P}_{\text {paper }}(\%)$ is the percentage of water in pressboard. Substituting our numbers in Table V to (12) gives:

$$
P_{\text {paper }}(\%)=14.1-0.093 \cdot W_{\text {oil }}(\mathrm{PPM}),
$$

The line is completely defined by the initial condition and the system configuration, i.e., independent of the final moisture measurement. The intersection of the mass conservation line with the moisture partition curves at $70^{\circ} \mathrm{C}$ indicates the equilibrium value for the system. From this curve, the final moisture in oil is about 115 PPM and the moisture in pa- 


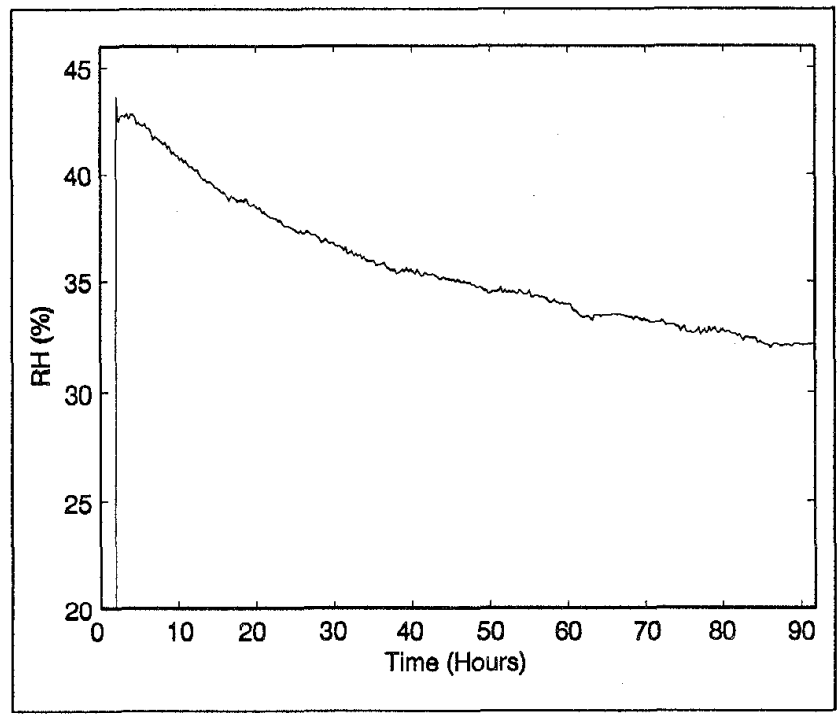

Fig. 11 The relative humidity of the oil decreases as the moisture diffuses from oil into pressboard

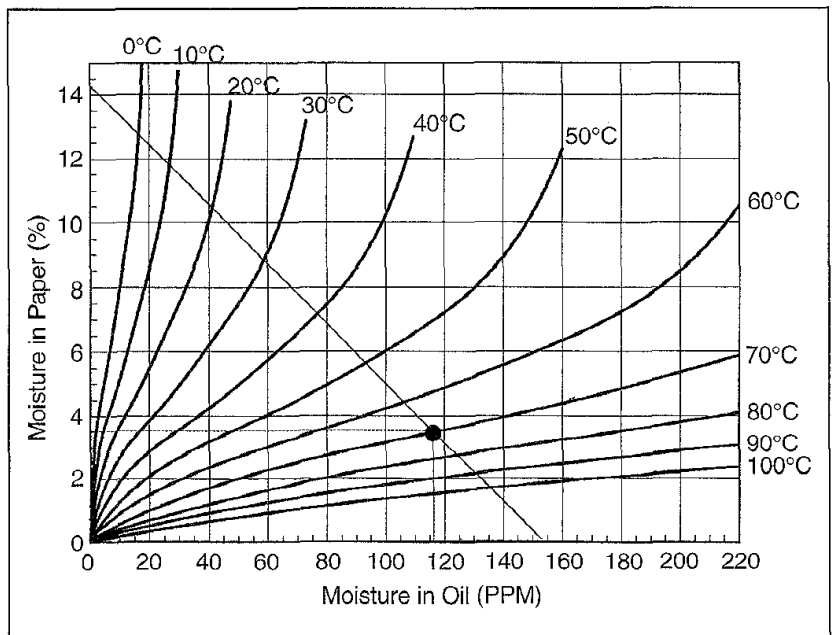

Fig. 12 System equilibrium operating point found using the moisture equilibrium curves for oil and paper system

per is about $3.5 \%$. This is consistent with the result derived from Method 1.

\section{Conclusions}

Several sets of classic moisture equilibrium curves were studied and a comparison is given for each method. Caution should be taken when using such curves because they differ from measurement techniques, data sources, and generating methods. An experimental case study shows that Oommen's curves match the experimental data best.

When the system is not in equilibrium, these equilibrium curves cannot be used to find the moisture in paper. A three-wavelength interdigital dielectrometry sensor developed at the MIT High Voltage Research Laboratory is able to measure the spatial profile of the moisture distribution in the pressboard $[35,36]$. This provides an alternative method when the transient system is not in equilibrium.

\section{Acknowledgments}

The authors are grateful for continuing financial support from the Electric Power Research Institute under WO 8619-01, managed by S. Lindgren, the National Science Foundation under Grant No. ECS-9523128, and the Demonstration of Energy-Efficiency Developments Scholarship from American Public Power Association, sponsored by Belmont Utility managed by T. McCarthy, and Link Fellowship Foundation. We would like to thank Dr. T. V. Oommen at ABB-ETI, P. J. Griffin at Doble Engineering, Dr. G. M. Urbani at Haefely Trench AG, and Prof. J. K. Nelson at RPI for valuable discussions and document supply.

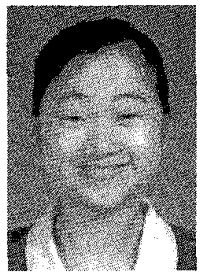

Yanqing Du (S'95) received the BS and MS degrees in electrical engineering from Northwestern Polytechnic University, Xi'an, China, in 1993 and 1994, respectively. From 1994 to present, she has been a research assistant and Ph.D. student in the Department of Electrical Engineering and Computer Science at Massachusetts Institute of Technology, Cambridge, Massachusetts. Her research interests include interdigital sensor measurements, moisture diffusion phenomena, electromagnetism, and signal processing for dielectric relaxation measurements. Du is the recipient of the 1995 and 1996 Demonstration of Energy-Efficiency Developments Fellowship from the American Public Power Association. She can be reached at 155 Mass. Ave., MIT, Cambridge, MA 02139, email: yanqing@mit.edu.

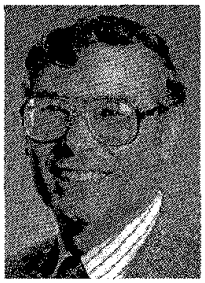

Markus Zahn received the BSEE and MSEE degrees in 1968 , the electrical engineers degree in 1969, and the Sc.D. degree in 1970, all from the Department of Electrical Engineering at the Massachusetts Institute of Technology. From 1970-1980 he was a professor of electrical engineering at the University of Florida, Gainesville, Florida. He joined the MIT faculty in 1980 and is now professor of electrical engineering working in the Laboratory for Electromagnetic and Electronic Systems. He is also director of the MIT VI-A internship program. Prof. Zahn is the author of a book and co-author of more than 100 technical publications and holds several patents. His fields of research and interest include electro-optical field and charge mapping measurements; flow electrification phenomena in electric power apparatus; development of capacitive and inductive sensors for measuring dielectric, conduction and magnetic properties of materials as well as related physical properties; electrohydrodynamic and electrokinetic interactions with charged and polarizable fluids; ferrohydrodynamic interactions with magnetizable fluids; and magnetic diffusion phenomena and forces for MAGLEV transportation applications. He is a fellow of the IEEE and presently serves as associate editor of the Transactions on Dielectrics and Electrical Insulation and chairman of the Liquid Dielectrics Committee. He was the Whitehead Memorial Lecturer at the 1998 CEIDP. 


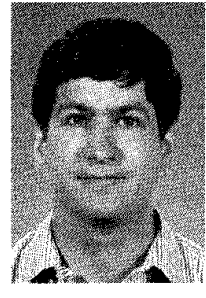

Bernard C. Lesieutre (S'86, M'93) received his BS, MS, and Ph.D. degrees from the University of Illinois at Urbana-Champaign, Illinois in 1986, 1988, and 1993, respectively. He joined the faculty of the Department of Electrical Engineering and Computer Science at MIT in 1993 and is associated with the Laboratory for Electromagnetic and Electronic Systems. His research involves the modeling, monitoring, and analysis of power apparatus and systems, and the study of nonlinear systems. He was the general chair of the 1996 North American Power Symposium and is a member of the IEEE and Eta Kappa Nu.

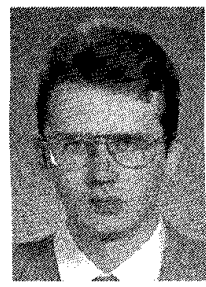

Alexander V. Mamishev received his BS degree in electrical engineering and physics from Kiev Polytechnic Institute, Kiev, Ukraine in 1992, and MS degree in electrical engineering from Texas A\&M University, College Station, Texas in 1994. He is currently enrolled in a $\mathrm{Ph} . \mathrm{D}$. program in electrical engineering at MIT. During his graduate studies, he was a recipient of the IEEE DEIS Fellowship, the IEEE PES T. Burke Hayes Award, the IEEE Vincent Bendix Award, the American Vacuum Society Graduate Research Award, the Link Foundation Energy Fellowship, the APPA DEED Scholarship, and several other distinctions. Mamishev is a co-author of more than 30 technical publications, including an IEEE encyclopedia chapter and two invited papers. His research interests include dielectrometry, interdigital sensors, electromagnetism, and power equipment optimization and diagnostics. He is a member of the DEIS and PES, the Electrostatics Society of America, the Materials Research Society, the American Society for Nondestructive Testing, the Electrochemical Society, the American Vacuum Society, Sigma Xi, Eta Kappa Nu, and the IEEE PES AC Field Effects Design Guide Task Force.

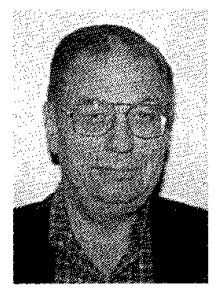

Stanley R. Lindgren is manager, power transformers, in the Substation Target of the Energy Delivery and Utilization Division of EPRI in Palo Alto, California. Before joining EPRI in 1986, he was with the Paragon Electric Co., Inc., Two Rivers, Wisconsin, a subsidiary of AMF, Inc., from 1979 to 1986, where he was manager of strategic planning and product acquisition. At RTE Corp., Waukesha, Wisconsin, he was product marketing manager for RTE's Small Power Transformer Division, 1971-1978. The products were three-phased pad-mounted, secondary unit substation and power transformers, $5000 \mathrm{KVA}$ and below. At Allis Chalmers, Milwaukee, he held various positions in product application and technical marketing for the Power Transformer Division, 1952-1971, involving all types of medium, large, and $\mathrm{EHV}$ power transformers. He obtained his BS in electrical engineering (power) from Kansas State University.

\section{References}

1. F. M. Clark, "Factors Affecting the Mechanical Deterioration of Cellulose Insulation," Transactions of Electrical Engineering, Vol. 61, pp. 742-749, October 1942.
2. J. Fabre and A. Pichon, "Deteriorating Processes and Products of Paper in Oil. Application to Transformers," 1960 International Conference on Large High Voltage Electric System (CIGRE), Paris, France, Paper 137, 1960.

3. H. P. Moser, Transformerboard, Special print of Scientia Electrica, translated by EHV-Weidmann Lim., St., Johnsbury, Vermont, USA, Section C, 1979.

4. A. J. Morin, M.Zahn, and J.R. Melcher, "Fluid Electrification Measurements of Transformer Pressboard/Oil Insulation in a Couette Charger," IEEE Transactions on Electrical Insulation, Vol. 26, No. 5, pp. 870-901, October 1991.

5. A. P. Washabaugh, P. A. von Guggenberg, M. Zahn, and J. R. Melcher, "Temperature and Moisture Transient Flow Electrification Measurements of Transformer Pressboard/Oil Insulation Using a Couette Facility," Proceedings of The $3^{\text {rd }}$ International Conference on Properties and Applications of Dielectric Materials, Vol. 2, Tokyo, Japan, pp. $867-870$, July $8-12,1991$.

6. W. A. Fessler, W. J. McNutt, and T. O. Rouse, "Bubble Formation in Transformers," EPRI Report EL-5384, EPRI, Palo Alto, CA, August 1987.

7. P. J. Griffin and J. Christie, "Effects of Water and Benzotriazole on Electrostatic Charge Generation in Mineral Oil/Cellulose Systems," Proceedings: Static Electrification in Power Transformers, EPRI TR-102480, Project 1499-99, June 1993.

8. T. O. Rouse, "Mineral Insulating Oil in Transformers," Electrical Insulation Magazine, Vol. 14, No. 3, pp. 6-16, May/June 1998.

9. "Relative Humidity," Britannica Online, 1994-1997 Encyclopedia Britannica, Inc, URL: http://www.britannica.com/.

10. G. Beer, G. Gasparani, F. Osimo, and F. Ross, "Experimental Data on the Drying-out of Insulation Samples and Test Coil for Transformers," CIGRE Paper No. 135, 1966.

11. B. Fallou, "Summary of Work Done at L.C.I.E. on the Paper-Oil Complex," internal report of Laboraroire centre des Industries electriques, France.

12. T. V. Oommen, "Moisture Equilibrium in Paper-Oil Systems," Proceedings of the Electrical / Electronics Insulation Conference, Chicago, IL, pp. 162-166, October 3-6, 1983.

13. R. B. Kaufman, E. J. Shimanski, and K. W. McFaydynen, "Gas and Moisture Equilibrium in Transformer Oil," Communication and Electronics, No. 19, pp. 312-318, July 1955.

14. D. N. Ewart, "Laboratory and Factory Measurements of Moisture Equilibrium in Power Transformer Insulation," GE TIS Report 60PT44, August 1960.

15. E. T. Norris, "High Voltage Power Transformer Insulation," Proceedings I.E.E., Vol. 110, No.2, pp. 433, February 1963.

16. J. K. Nelson, "Dielectric Fluids in Motion," IEEE Electrical Insulation Magazine, Vol. 10, No. 3, pp.16-28, May/June 1994.

17. A. G. Schlag, "The Recovery Voltage Method for Transformer Diagnosis," Tettex Instruments booklet.

18. R. Jeffries, "The Sorption of Water by Cellulose and Eight Other Textile Polymers," Journal of the Textile Institute Transactions, Vol. 51, No. 9 , pp. 339-374, 1960.

19. J. Reason, "Cost-effective Transformer Maintenance," Electrical World, pp. 17-30, October 1997.

20. Handbook of Chemistry and Physics, D-94, 46th Edition, the Chemical Rubber Co., Cleveland, Ohio, 1966. 
21. J. D. Piper, “Moisture Equilibrium Between Gas Space and Fibrous Materials in Enclosed Electric Equipment," AlEE Transactions, Vol. 65, pp. 791-797, December 1946.

22. A. R. Urquhart and A. M. Williams, "The Moisture Relations of Cotton, The Effect of Temperature on the Absorption of Water by Soda-Boiled Cotton," Joumal, Textile Institute (Manchester, England), Vol. 15, pp. T559, 1924.

23. S. M. Neale and W. A. Stringfellow, "The Primary Sorption of Water by Cotton," Transactions, Faraday Society (London, England), Vol. 37, pp. $525,1941$.

24. C. C. Houtz and D. A. McLean, "Adsorption of Water by Papers at Elevated Temperatures," Joumal of Physical Chemistry, Baltimore, Md., Vol. 43, pp. 309-321, 1939.

25. L. M. Pidgeon and O. Maass, "The Adsorption of Water by Wood," Journal, American Chemical Society, Washington, D.C., Vol. 52, pp. $1053,1930$.

26. W. W. Guidi and H. P. Fullerton, "Mathematical Methods for Prediction of Moisture Take-up and Removal in Large Power Transformers," Proceedings of IEEE Winter Power Meeting, C-74 242-244, 1974.

27. T. V. Oommen, "Moisture Equilibrium Charts for Transformer Insulation Drying Practice," IEEE Transaction on Power Apparatus and Systems, Vol. PAS-103, No. 10, pp. 3063-3067, October 1984.

28. S. Glasstone, Textbook of Physical Chemistry, Second Edition, D. Van Nostrand Co., 1946, Chapter XIV.

29. T. V. Oommen, E. M. Petrie and S. R. Lindgren, "Bubble Generation in Transformer Windings Under Overload Conditions," Minutes of the
Sixty-Two Annual International Conference of Doble Clients, Sec. 8-5.1, March 1995.

30. P.J. Griffin, C. M. Bruce, and J. D. Christie, "Comparison of Water Equilibrium in Silicone and Mineral Oil Transformers," Minutes of the Fifty-Fifth Annual International Conference of Doble Clients, Sec. 10-9.1, 1988.

31. S. D. Foss, "Power Transformer Drying Model," Report prepared for General Electric Company, Large Transformer Operation, Pittsfield, MA, and Consolidated Edison Corp., New York, NY, by Dynamic Systems, Pittsfield, MA, 1987.

32. P. F. Ast, "Movement of Moisture through A50P281 Kraft Paper (Dry and Oil-Impregnated," test report HV-ER-66-41, General Electric, June 1966.

33. E. K. Steele, "Moisture Redistribution in Simulated Transformer Paper-Oil Systems," memo report MATL 70-37, General Electric, November 1970.

34. Shell Diala Oils, Shell Oil Company, One Shell Plaza, 900 Louisiana Street, Houston, Texas 77002, (800)231-6950, Shell Lubricants Technical Bulletin SOC: 39-92.

35. Y. Du, M. Zahn, A. V. Mamishev, and D. E. Schlicker, "Moisture Dynamics Measurements of Transformer Board Using a Three-Wavelength Dielectrometry Sensor," IEEE International Symposium on Electrical Insulation, Montreal, Quebec, Canada, pp. 53-56, June 1996.

36. Y. Du, M. Zahn, and B. C. Lesieutre, "Dielectrometry Measurements of Effects of Moisture and Anti-Static Additive on Transformer Board," IEEE Conference on Electrical Insulation and Dielectric Phenomena, Minneapolis, MN, USA, pp. 226-229, October 1997. 